\title{
CAMINHAR E ESCREVER: \\ LINHAS FUNÂMBULAS PROLIFERANDO CIDADES
}

WALK AND WRITE: TIGHTROPE-LINES PROLIFERATING CITIES

CAMINAR Y ESCRIBIR: LÍNEAS FLOJAS PROLIFERANDO CIUDADES

\author{
Kátia Maria Kasper ${ }^{1}$ \\ André Pietsch Lima \\ Gabriela de Sousa Tóffoli ${ }^{3}$ \\ Thalita Alves Sejanes ${ }^{4}$
}

Resumo: Escreve-se pela cidade, caminhando e alinhavando suas linhas aos corpos em trânsito. Caminha-se entre vegetais, minerais, percorrendo as delicadezas de tempos brutos com uma escritafilosofia das existências mínimas. Traçando entre fissuras, frestas e corpos que (des)encontram.

Palavras-chave: Cartografia; escrita; Deligny.

Abstract: Write by the city, walking and basting its lines to the bodies in motion. Walk among vegetables, minerals, covering the niceties of rough times with a philosophy-writing of the lesser existences. Tracing between fissures, gaps and bodies that (mis)match.

Keywords: Cartography; write; Deligny.

Resumen: Se escribe por la ciudad, caminando y cosiendo sus líneas a los cuerpos en tránsito. Se camina por entre vegetales, minerales, recorriendo las menudencias de tiempos brutos con un escrito-filosofía de las existencias mínimas. Trazando por entre las fisuras, grietas y cuerpos que (des)encuentran.

Palabras clave: Cartografía; escrito; Deligny.

\section{Corpo do texto}

Quando é que brota o que habita?

Quando é que brota aquilo que me habita?

Quando é que brotam os que habitam?

\footnotetext{
${ }^{1}$ Universidade Federal do Paraná.

${ }^{2}$ Universidade Federal do Paraná.

${ }^{3}$ Universidade Federal do Paraná.

${ }^{4}$ Universidade Federal do Paraná.
} 


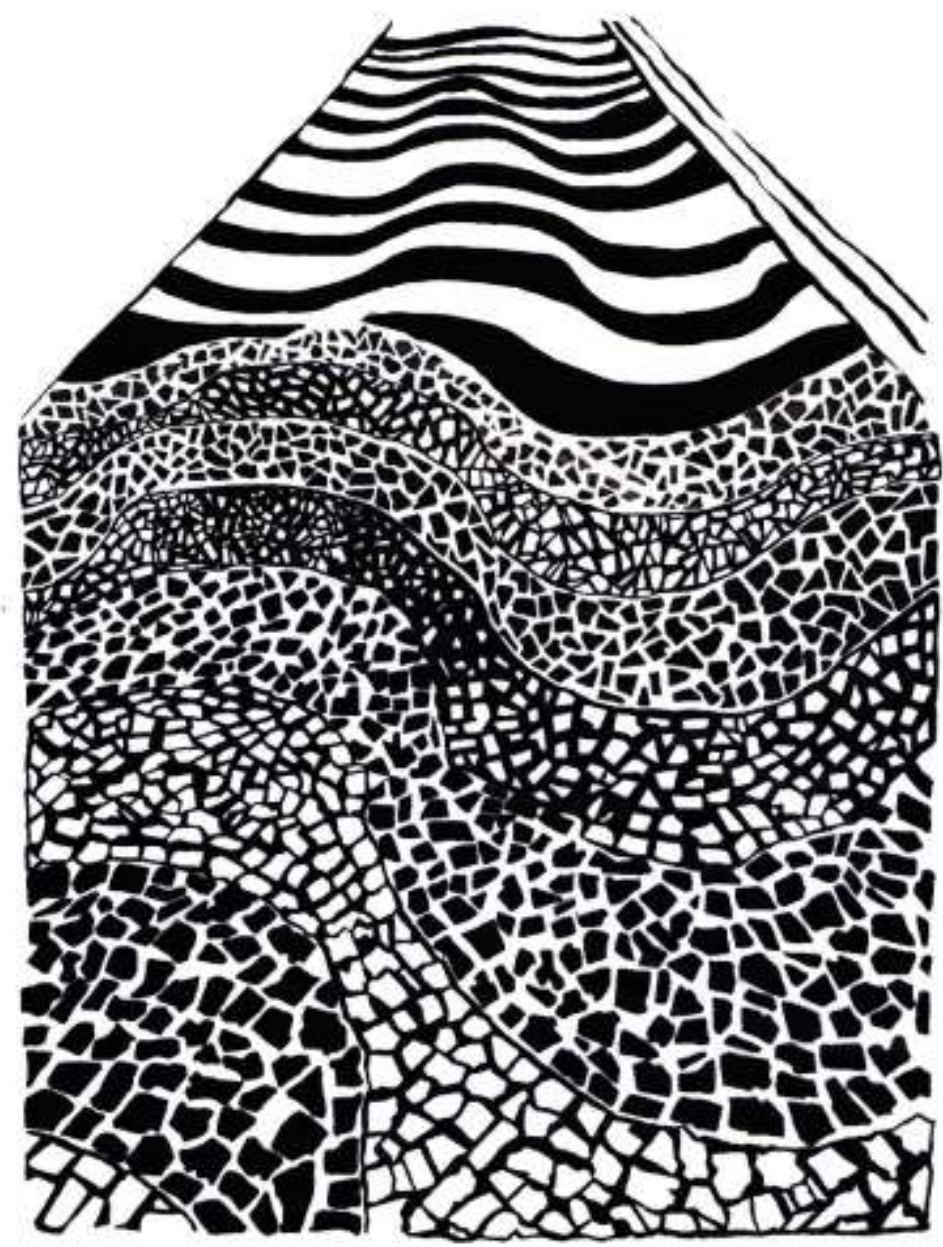

Figura 1 - Fonte: Elaboração própria ${ }^{5}$

(In)servíveis: impregnações morfológicas.

Há uma praça na cidade. Em seu centro, altiva como esfinge havia uma senhora. Sua dura pele recoberta de pequeninos musgos, líquens e gotículas que refletem com suavidade as luzes de uma manhã de outono. Perto dali um casal passa de mãos dadas. Duas outras criaturas silenciosas param diante dela. A humanidade parecia desfilar à sua frente. Ela, absolutamente sozinha. Nela, o sorriso e as lágrimas de Ontem. Os amores. Os abraços. As amizades. Os desejos. A alegria e a tristeza. Os arrepios e o luto. As caminhadas à toa. Todas as entranhas da terra. As constelações do céu. A Indiferença aos deuses e aos homens.

\footnotetext{
${ }^{5}$ Os desenhos deste ensaio foram realizados em tinta nanquim sobre papel e são procedimentos de pesquisa com a cidade, inspirados pelos escritos, trajetos e traços de Fernand Deligny.
} 
Mancham a cidade de rosa.

Sussurram cantos e clareiras.

Sem pressa ou pudor a cidade é varrida.

$$
* * *
$$

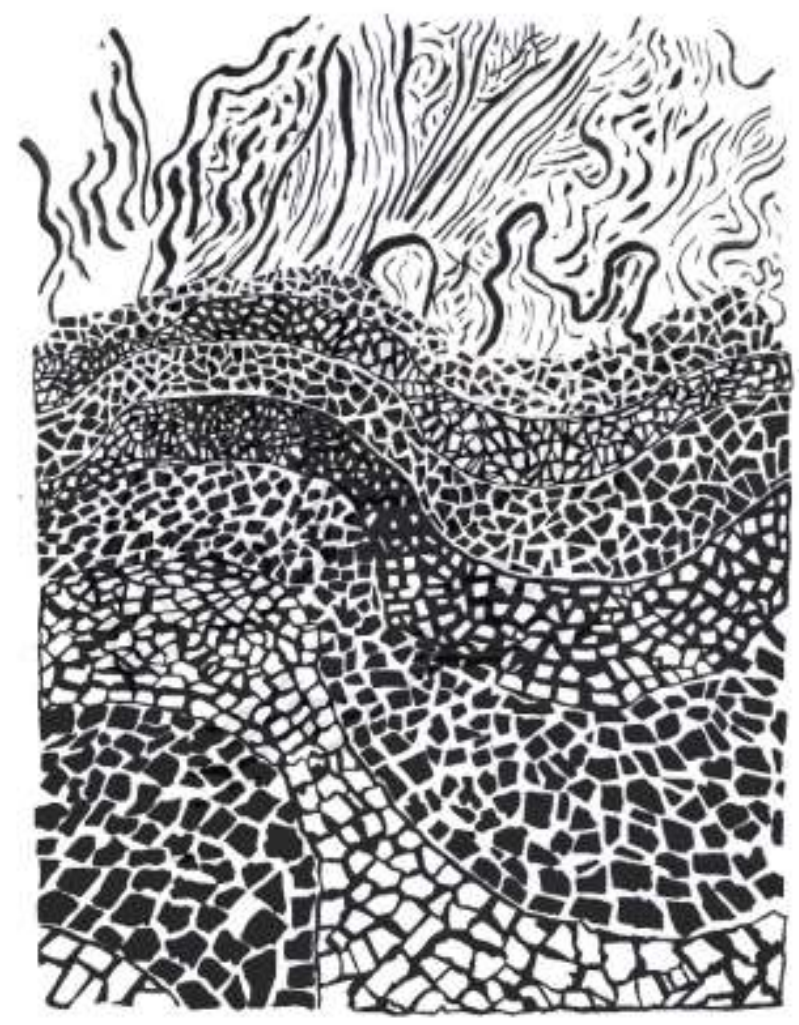

Figura 2 - Fonte: Elaboração própria

linhas

emaranhadas

nas rodas de bicicletas

ninhos e teias em cantos e copas

fios de alta tensão

emaranhar

nos trajetos que o gesto traça

amplia presença,

convida escuta,

pratica demora,

desacelera

“traçar é um agir" (DELIGNY, 2015).

percebe, observa e cria linhas: cria circunstâncias (DELIGNY, 2018). 


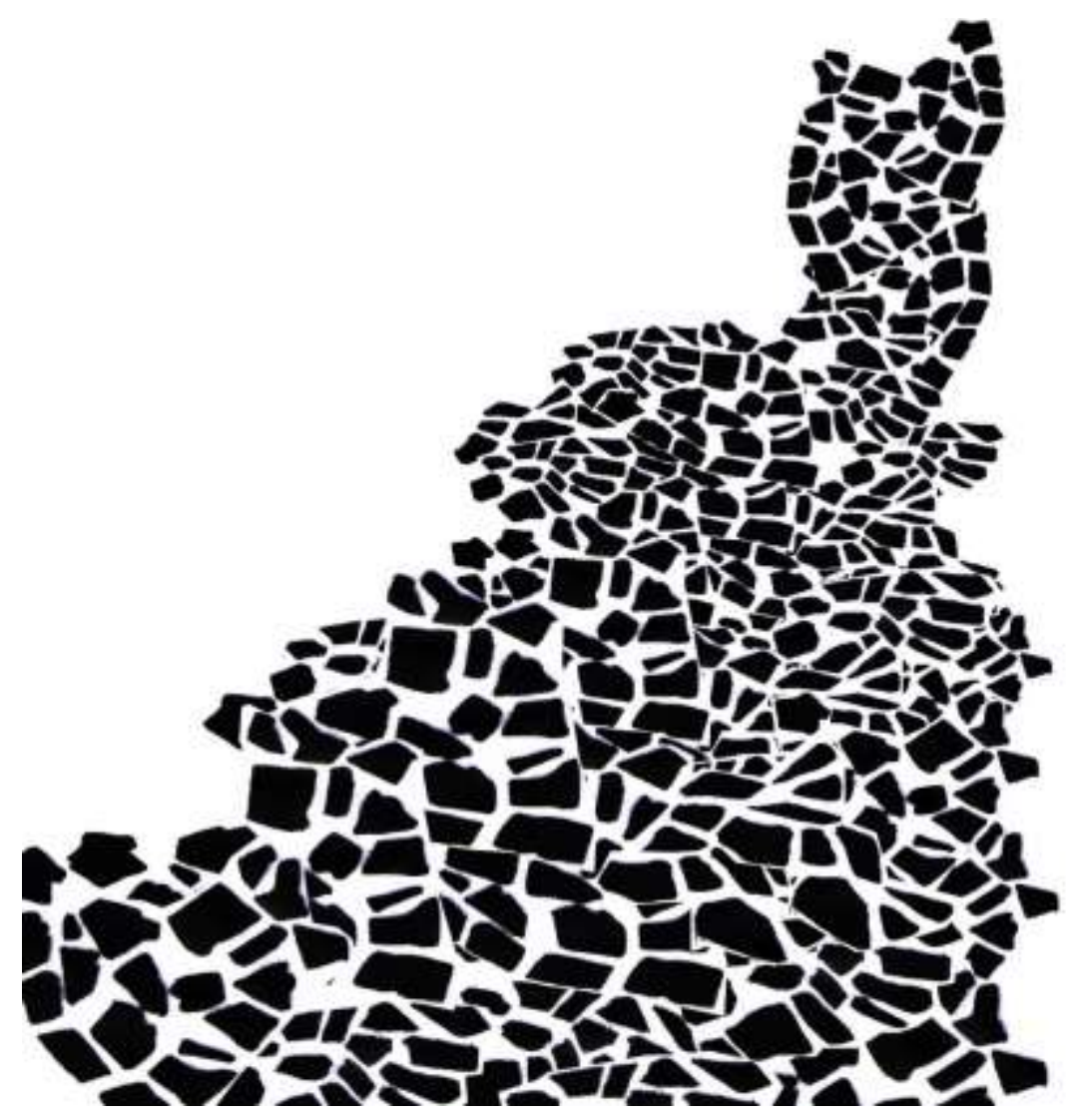

Figura 3 - Fonte: Elaboração própria

$* * *$

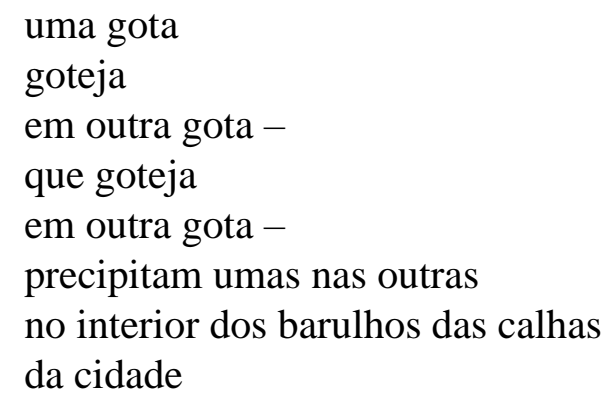

são muitas as pequenas formigas que saem das frestas do muro

um vão no museu convoca o fora pra dentro e o mesmo com o contrário

co-interferências nas imagens refletidas das paredes de vidro

cachorros correm pra lugar algum, ipês derramam suas flores num gramado que acomoda gente e bicho e cangas e cervejas e vinhos

dali em diante não importa nada que cruze um caminho

qualquer

num quase aquário de ângulos retos, uma moça de gola alta, uma garçonete, mesas e cadeiras, designers e suas assinaturas esperam...

- um café, por favor! 
ali na esquina uma dobra na abertura da rua que alarga até a avenida origamis

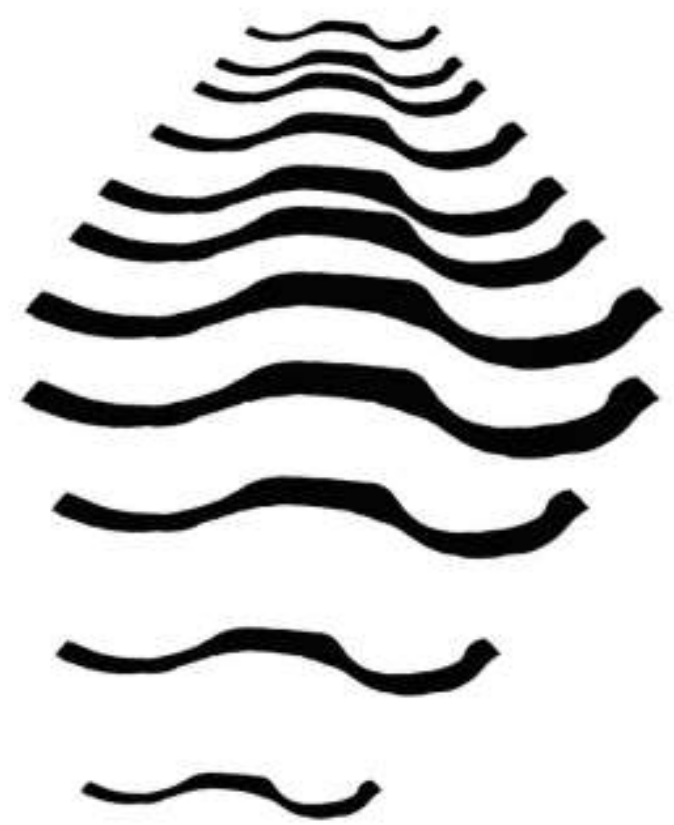

Figura 4 - Fonte: Elaboração própria

$* * *$

Da sacada do primeiro andar ele cumprimenta o síndico e seu cachorro babante. Desde a entrada da farmácia ao estacionamento do supermercado é possível vê-lo ali. Um banquinho, pernas cruzadas, um tanto arcado pela idade, aperta os olhos para ver mais longe.

É semifinal: no estádio vazio, os jogadores driblam, correm, escutam o técnico, a sonoridade límpida, as arquibancadas lá fora, na praça uma multidão comemora o quase título e mascarados passam pelo centro.

Fora!

Caminham em compassados um metro e meio de distância.

Fora!

Carregam faixas, cartazes, angústias.

Fora!

Miséria, desconforto, força.

Fora!

Um kibe na boca maldita.

Os sabiás estão ouriçados, cantam disparatados de lá pra cá É a época, diz Rosa.

Sobrevoam a cidade, ora em busca de alguma coisa ora, em derivas ao vento (CARERI, 2013) 
param para cumprimentar o vizinho

sobem com a inesperada rajada

beliscam os frutos daquela árvore

se reúnem na copa outra

conexões passará-geiras,

rastros de um mapa nômade.

Quase dá pra ver o intenso arfar do vento balançando as árvores de um lado a outro. Assopram heavy metal nos frisos das janelas.

as mocinhas da cidade

as mocinhas cobertas

de tempestade

as mocinhas de areia

da cidade

as mocinhas da cidade cobertas pela areia da tempestade

$* * *$

vergalhões de metal sustentam o ar

no antes

vergalhões de metal elevando o nada

antes

vergalhões vizinhos de outros vergalhões

antes

dos concretos

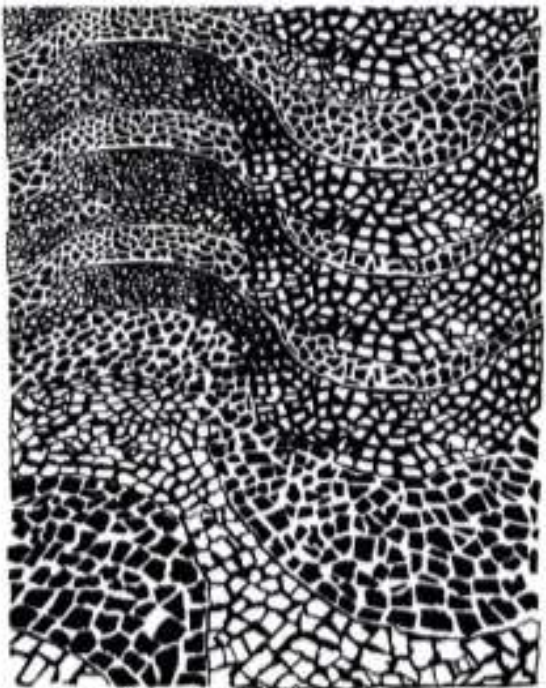

Figura 5 - Fonte: Elaboração própria 
Batem os copos num tintim dissonante:

um homem e seu cachorro dividem restos da feira

profanam a calçada

almoçam na mesa de pedras brutas

inventam um jogo de dividir o indivisível.

uma coisa que respira em outra coisa

uma coisa que transpira outra coisa

uma coisa que respira em outra coisa

uma coisa que suspira outra coisa

sugerem intenções de beija-flor

Num trajeto, das cinco às seis da manhã

ela passa por três cidades

bem sabe dizer qual rio e qual linha qualquer divide uma da outra

ela acha estranho, um passo pra cá é aqui

um passo pra lá é acolá

dá vontade de ficar metade aqui, metade lá

metade dentro, metade fora

da cidade subjetiva (GUATTARI, 1992)

Entre carros e bicicletas, uma criança persegue o avião de papel. Grita pula e canta. Grita pula e canta. Grita pula e. Canta. Grita. Pula e. Canta no. Canta no canto do susto da mulher que passa.

Variando meteorologicamente o estudante segue apressado em direção ao ponto do ônibus. Caminha afastando-se dos ruídos urbanos, capturando os sons ao redor. Bem como o texto queria: errante, vagabundo. Como se caminhasse entre os fios de uma rede (DELIGNY, 2015), acaba por não chegar ao ponto. 


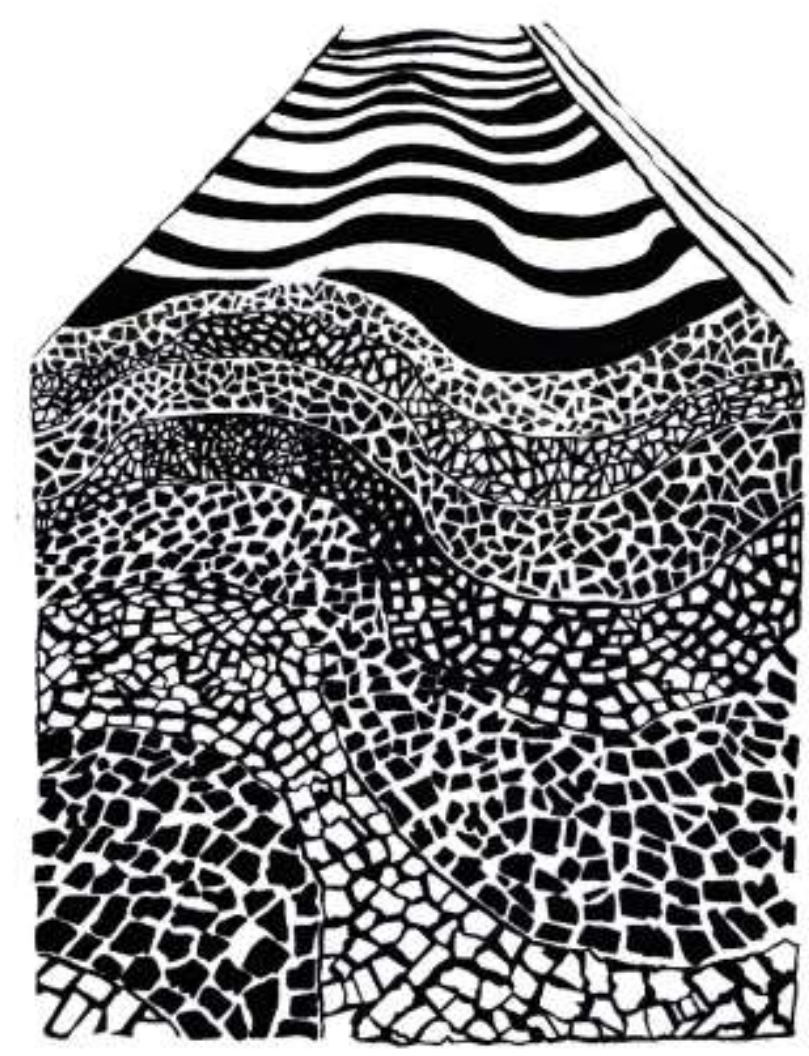

Figura 6 - Fonte: Elaboração própria

$* * *$

Fio a fio, uma escrita-filosofia (GROS, 2011). O caminhar e a cidade cartografam-se (ROLNIK, 2007; DELIGNY, 2015) em texto, mapeando (des)encontros entre trajetos vagos, desenhos da caminhada, fissuras, frestas e corpos.

Fio a fio, uma escrita à noite, entre ficção, narrativas, outras realidades

naquela rua

larga

que abriga quatro bicicletas

ao mesmo tempo

rua das infâncias

que vivem no aqui e agora

na memória de um sonho

vive lá

outra

num bairro

outro

existe à sua maneira

emaranhada em variados planos

que compõem uma existência (LAPOUJADE, 2017) e -

como nas calçadas quando minúsculos

gestos instauram ínfimas

mortes outonais entre

seres que digerem 
a massa verde e úmida

de uma folha

expondo um

desenho de dentro

e os esconderijos

das teias de veias

secas e vivas.

\section{Referências}

CARERI, Francesco. Walkscapes: o caminhar como prática estética. Trad. F. Bonaldo. São Paulo: Ed. Gustavo Gilli, 2013.

DELIGNY, Fernand. O aracniano e outros textos. Trad. L. Malimpensa. São Paulo: n-1 edições, 2015.

DELIGNY, Fernand. Os vagabundos eficazes: operários, artistas, revolucionários: educadores. Trad. M. Miguel. São Paulo: n-1 edições, 2018.

GUATTARI, Félix. Caosmose: um novo paradigma estético. Trad. A. L. Oliveira e L. C. Leão. São Paulo: Editora 34, 1992.

GROS, Frédéric. Marcher, une philosophie. Paris: Flammarion, 2011.

LAPOUJADE, David. As existências mínimas. Trad. H. S. Lencastre. São Paulo: n-1 edições, 2017.

ROLNIK, Suely. Cartografia sentimental: transformações contemporâneas do desejo. 2. ed. Porto Alegre: Sulina; Ed. UFRGS, 2007.

\section{Sobre os autores}

Kátia Maria Kasper. Professora do Setor de Educação da Universidade Federal do Paraná (UFPR). Graduada em Pedagogia (UNICAMP). Mestre e Doutora em Educação (UNICAMP). Professora do Programa de Pós-Graduação em Educação: Teoria e Prática de Ensino (UFPR) e do Programa de Pós-Graduação em Educação em Ciências e em Matemática (UFPR).

E-mail: katiakasper@uol.com.br.

André Pietsch Lima. Professor do Setor de Educação - Universidade Federal do Paraná (UFPR); Doutor em Educação - Universidade Federal do Rio Grande do Sul (UFRGS).

E-mail: andrepietschlima@gmail.com.

Gabriela de Sousa Tóffoli. Graduada em Pedagogia (Universidade Federal do Paraná), tem mestrado em Educação e Ciências e em Matemática (Universidade Federal do Paraná) e doutoranda do programa de Pós Graduação em Educação em Ciências e em Matemática (Universidade Federal do Paraná). É professora da educação básica no município de Araucária - PR. Tem experiência na área de educação, com pesquisa em andamento nos seguintes temas: subjetividade, cidade, ecosofia e formação.

E-mail: gabrielatoffoli@gmail.com. 
André Pietsch Lima. Artista visual e pesquisadora. Licenciada em Artes Visuais pela Faculdade de Artes do Paraná (UNESPAR-PR), tem mestrado em Educação em Ciências e Matemática pela UFPR e doutoranda do programa de Pós-Graduação em Educação em Ciências e em Matemática (Universidade Federal do Paraná). Professora de artes na educação básica. E-mail: thalitasejanes@gmail.com. 